\title{
IMPLEMENTASI MOVING AVERAGE TERHADAP EFEKTIVITAS SALDO AKUN TRADING BITCOIN
}

\author{
Enggar Irawan ${ }^{1)}$, Falentino Sembiring ${ }^{2)}$, Sudin Saepudin ${ }^{3)}$ Adithia Erfina $^{4)}$ \\ Program Studi Sistem Informasi, Universitas Nusa Putra Sukabumi Jl. Raya Cibolang No. \\ 21Sukabumi, Jawa Barat, 43152 Indonesia, Tlp. 0266210594 \\ e-mail: enggarukei@gmail.com ${ }^{1)}$, falentino.sembiring@nusaputra.ac.id \\ ${ }^{2)}$,sudin.saepudin@ nusaputra.ac.id ${ }^{3}$ ),adithia.erfina@ nusaputra.ac.id ${ }^{4}$
}

\begin{abstract}
ABSTRAK
Bitcoin saat ini sudah mulai di kenal sebagai asset digital bagi para milenial dan tidak hanya menginvestasikan dana dalam instrument investasi tradisional seperti saham, obligasi, dan reksadana, generasi milenial juga mulai menginvestasikan dana dalam bentuk mata uang Criptocurrency dan menjadi sebuah tren investasi baru yang sedang meningkat di Indonesia dan merupakan instrument investasi paling menguntungkan di decade ini. Permasalahan yang sering muncul yaitu salah satunya adalah Cryptocurrency tidak bisa di prediksi dengan mudah, salah langkah dalam menganalisis dan prediksi akan berakibat fatal terhadap asset yang dimiliki, sehingga dapat menimbulkan kerugian besar ketika pelaku investor/trader melakukan keputusan tanpa berdasarkan analisa dan prediksi yang tepat. Algoritma MA dapat meminimalisir kesalahan dalam prediksi yang sering keliru dilakukan para investor/trader dalam memprediksi yang sering didasarkan pada intuisi dan emosi. Penelitian ini bertujuan untuk melihat hasil akurasi dari algoritma MA terhadap peramalan harga Bitcoin dan menentukan di posisi mana algoritma ini lebih efektif untuk digunakan dalam strategi analisis sehingga diharapkan informasi ini dapat dijadikan acuan untuk para pelaku trader/investor dalam menentukan keputusan Buy, Sell or Hold dalam berinvestasi dan mengurangi kesalahan proses perdagangan jual dan beli pada Bitcoin.
\end{abstract}

Kata Kunci: Akurasi, Efektivitas, Moving Average, Bitcoin, Prediksi

\section{ABSTRACT}

Bitcoin is now starting to be recognized as a digital asset for millennials and not only investing funds in traditional investment instruments such as stocks, bonds, and mutual funds, millennials are also starting to invest funds in cryptocurrencies and become a new investment trend that is on the rise. in Indonesia and is the most profitable investment instrument in this decade. The problems that often arise are that one of them is that Cryptocurrency cannot be predicted easily, a wrong step in analyzing and predicting will be fatal to the assets owned so that it can cause big losses when investors/traders make decisions without the right analysis and predictions. The EMA and MA algorithms can minimize errors in predictions that are often wrongly made by investors/traders in predicting which are often based on intuition and emotion. This study aims to see the results of the accuracy of the EMA and MA algorithms for Bitcoin price forecasting and determine in which position this algorithm is more effective for use in analytical strategies so that it is hoped that this information can be used as a reference for traders/investors in determining Buy decisions, Sell or Hold in investing and reduce errors in buying and selling trading processes on Bitcoin.

Keywords: Accuration, Efectivities, Moving Average, Bitcoin, Prediction

\section{PENDAHULUAN}

Di dekade ini para milenial sudah mulai melek terhadap perkembangan teknologi keuangan dan Criptocurrency menjadi salah satu sektor yang paling banyak diminati untuk melakukan perdagangan/investasi sehingga transaksi jual beli tidak dapat dihindari. Dengan pesatnya perkembangan teknologi, proses transaksi pun mulai mengalami perkembangan hingga saat ini proses jual beli bisa dilakukan melalui media internet. Bitcoin adalah salah satu Criptocurrency yang paling banyak digunakan oleh para pelaku trader/investor untuk melakukan perdagangan dan investasi sehingga memiliki nilai pertukaran yang sangat tinggi. [1]

Tindakan memprediksi dan menganalisis kondisi ekonomi adalah peran paling penting dalam berinvestasi. Untuk menghindari kekeliruan dalam pengambilan keputusan seorang trader/investor yang sering didasarkan pada emosi dan intuisi, model prediksi yang akurat dan tepat sangat diperlukan.

Moving Average adalah salah satu model metode indikator peramalan yang menghitung rata-rata suatu nilai runtut waktu dan kemudian digunakan untuk memperkirakan nilai pada periode selanjutnya. Moving Average atau Ratarata Bergerak diperoleh melalui penjumlahan dan pencarian nilai rata-rata dari sejumlah periode tertentu, kemudian menghilangkan nilai terlamanya dan menambah nilai baru. [2]

Penelitian ini bertujuan untuk melihat hasil akurasi dari algoritma MA terhadap peramalan harga Bitcoin dan menentukan di posisi mana algoritma ini lebih efektif untuk digunakan dalam strategi analisis sehingga diharapkan informasi ini dapat dijadikan acuan untuk para pelaku trader/investor dalam menentukan keputusan Buy, Sell or Hold dalam berinvestasi dan mengurangi kesalahan proses perdagangan jual dan beli pada Bitcoin. 


\section{TINJAUAN PUSTAKa}

Terdapat penelitian terdahulu yang sejalan dalam penelitian ini yaitu "Analisis Tingkat Akurasi Algoritma Moving Average Terhadap Pergerakan Uang Elektronik Bitcoin". Hasilnya adalah teknik buy dengan menggunakan algoritma SMA 12 dengan 1 periode $1 \mathrm{D}$ (hari) dalam 5 tahun menghasilkan per 100 transaksi dimana 25 transaksi prediksi menghasilkan benar dan 75 prediksi salah. Pada transaksi Sell dengan bantuan algoritma SMA 12 pada 1 periode $1 \mathrm{D}$ (hari), menghasilkan per 100 transaksi 63 prediksi benar dan 37 prediksi salah sehingga hasil dan tingkat kebenaran pada teknik Buy / Beli sebesar 63\% dan pada tingkat kebenaran pada teknik Sell /jual sebesar 25\% pada time periode Day 12 atau 12 hari. [2]

Sedangkan dalam penelitian lain yang berjudul "Bitcoin Meets Google Trends and Wikipedia: Quantifying the Relationship Between Phenomena Of The Internet Era" menyebutkan bahwa dalam penelitian ini dengan cara menghubungkan dua fenomena tahun-tahun terakhir. Antara Bitcoin dan kueri penelusuran Google Trends dan Wikipedia. Untuk mempelajari hubungan mereka disebutkan bahwa dalam faktor peningkatan harga Bitcoin tidak hanya permintaan pencarian (Supply And Demand), tetapi ada asimetri yang jelas antara efek peningkatan minat dalam mata uang yang saat berada di atas atau di bawah nilai trennya.[5]

\section{MetodologI}

Penelitian ini menggunakan alur kerangka berpikir sebagai berikut dalam gambar 1.

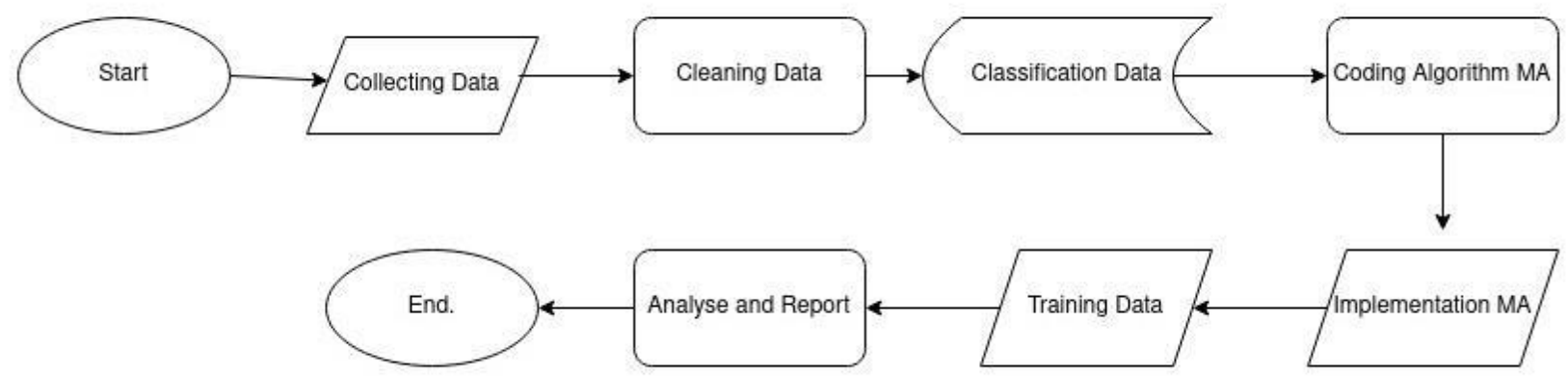

Gambar 1. Kerangka Berfikir

Terdapat 7 tahap dalam pengujian dalam penelitian ini

1. Tahap Pengumpulan Data

Data diambil dari data publik yang terdapat dalam website Investing.com dan data center yang berada dalam aplikasi MT4.

2. Tahap Cleaning Data

Pada tahap ini data di bersihkan "(Cleaning)" dari column dan rows yang tidak valid untuk memastikan proses dalam pengolahan data berjalan normal.

3. Klasifikasi Data

Proses ini dilakukan dengan mengklasifikasi data berdasarkan time frime yang berada dalam MT4.

4. Coding Algoritma MA

Pada tahapan ini peneliti menggunakan bahasa Pemrograman MQL4 yang dibantu dengan MetaEditor yang terdapat dalam aplikasi MT4.

5. Implementasi MA

Tahapan ini adalah menerapkan algoritma yang sebelumnya sudah dibangun kedalam MT4 dengan bantuan MetaEditor.

6. Training Data

Training Data adalah proses dimana data akan di uji oleh algoritma yang sudah dibangun setelah melalui tahap cleaning data dan classification data.

7. Analisis dan Laporan

Pada tahap ini proses pengujian dari tahapan 1 hingga 6 akan menampilkan berbagai informasi dari hasil pengujian dan menghasilkan tingkat akurasi dan efektivitas algoritma MA.

\section{Moving AVERAGE}

Moving Average adalah sebuah model indikator peramalan dalam teknik trading/investasi. Dalam statistik, ratarata bergerak adalah penghitungan yang digunakan untuk menganalisis titik data dengan membuat rangkaian ratarata dari subset berbeda dari kumpulan data lengkap. Di bidang keuangan, moving average (MA) adalah indikator 
saham yang umum digunakan dalam analisis teknikal. Alasan untuk menghitung rata-rata pergerakan suatu saham adalah untuk membantu memperlancar data harga dengan membuat harga rata-rata yang terus diperbarui. Dengan menghitung rata-rata bergerak, dampak fluktuasi acak jangka pendek pada harga saham selama jangka waktu tertentu dapat dikurangi.[2]

The Formula for SMA is:

$\mathrm{SMA}=\frac{A_{1}+A_{2}+\ldots+A_{n}}{n}$

where:

$$
\begin{aligned}
& A_{n}=\text { the price of an asset at period } n \\
& n=\text { the number of total periods }
\end{aligned}
$$

Gambar 2. Formula Simple Moving Average[6]

Dengan menghitung nilai dari harga dalam periode tertentu dan membagi dengan jumlah total periode.

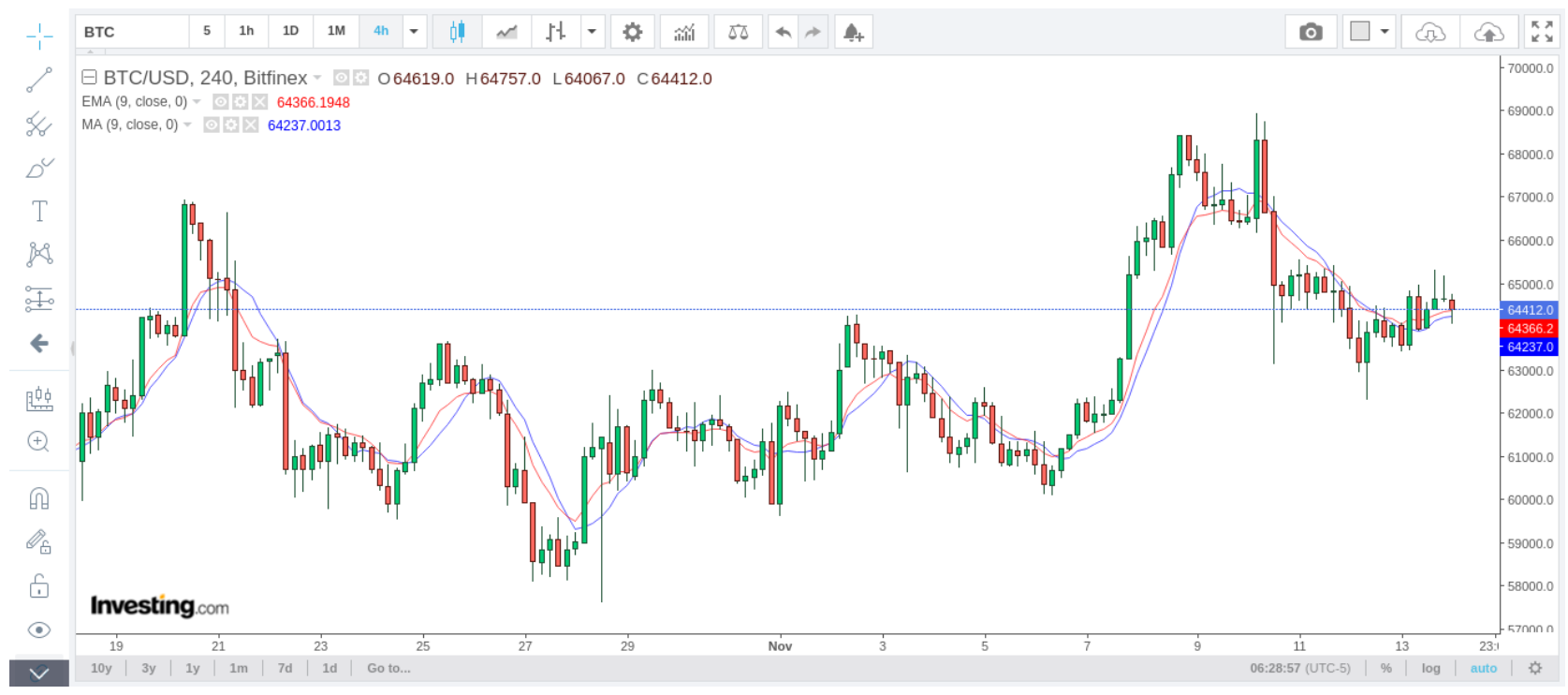

Gambar 3. Pergerakan Harga Bitcoin pada Investing.com

Dalam perhitungan Moving Average dapat dilakukan dengan melihat nilai dari harga pada periode waktu tertentu dan membaginya dengan jumlah total periode. Pada grafik yang terdapat dalam gambar 3 menunjukan harga penutup pada Bitcoin dengan time frame $\mathrm{H} 4$ (4 Jam) sebagai berikut:

H4 1: 64.307 .1

H4 2: 64.662 .8

H4 3: 64.662 .5

H4 4: 64.646.9

Untuk menghitung nilai periode diatas menggunakan MA adalah:

$\mathrm{MA}=(64.307 .1+64.662 .8+64.662 .5+64.646 .9) / 4$

$\mathrm{MA}=258,227 / 4$

$\mathrm{MA}=64,569$

Hasil dari H4 bar 5 adalah 64,569.

Hasil akan dikalkulasikan secara otomatis oleh algoritma dalam program MT4. Secara otomatis akan melakukan tindakan buy, sell or hold ketika transaksi Buy jika harga berjalan diatas SMA 12 Poin dan Transaksi Jual jika harga berjalan dibawah SMA 12 Poin. Dalam penelitian ini, menggunakan MQL4 sebagai dasar bahasa 
JURSISTEKNI (Jurnal Sistem Informasi dan Teknologi Informasi) Vol 3, No.3, September 2021: Hal 41 - 48 ISSN. P: 2715-1875, E: 2715-1883

program pembuatan robot algoritma MA untuk melakukan proses transaksi secara otomatis.

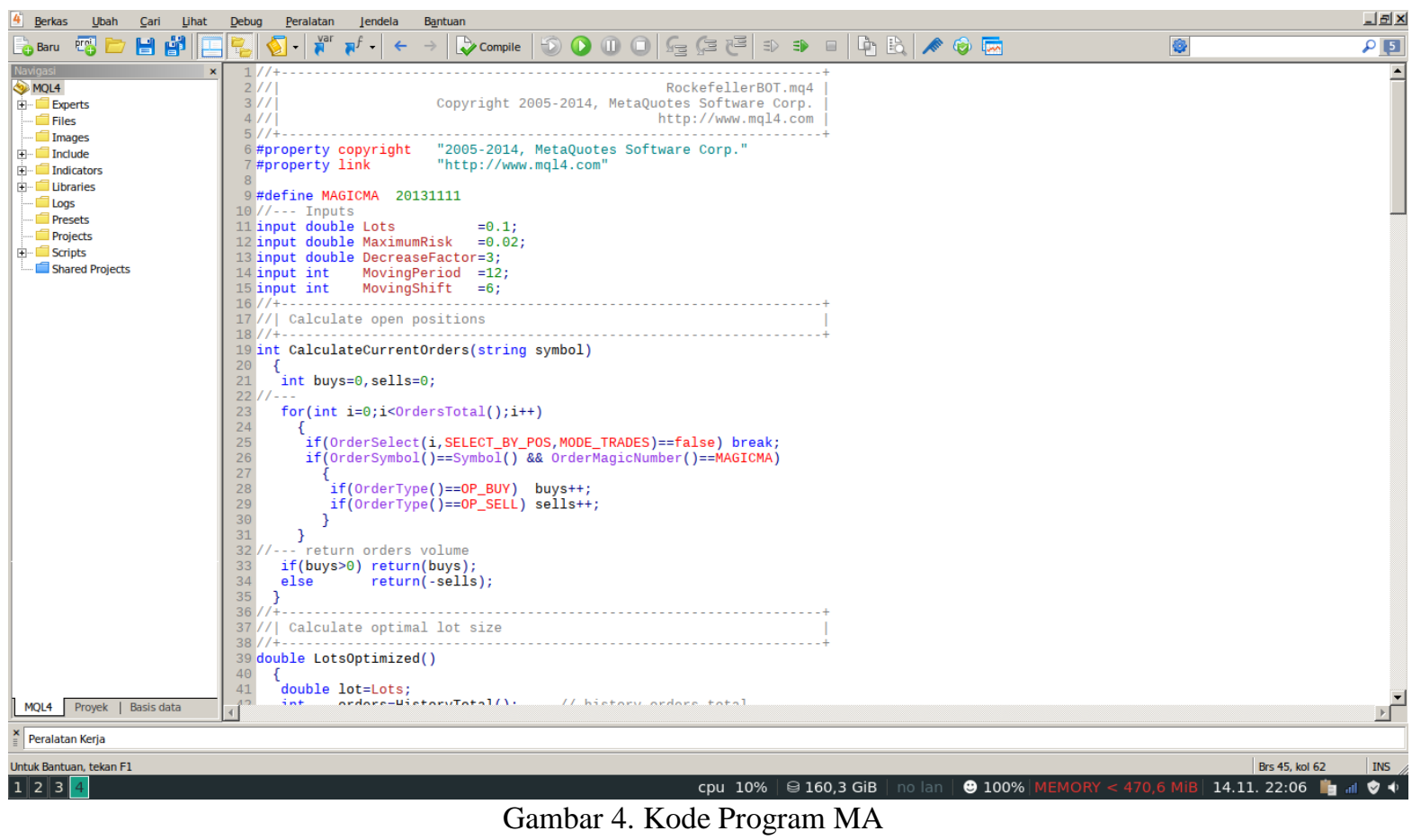




\section{EFEKTIVITAS MOVING A VERAGE TERHADAP SALDO PADA SETIAP TIME FRAME}
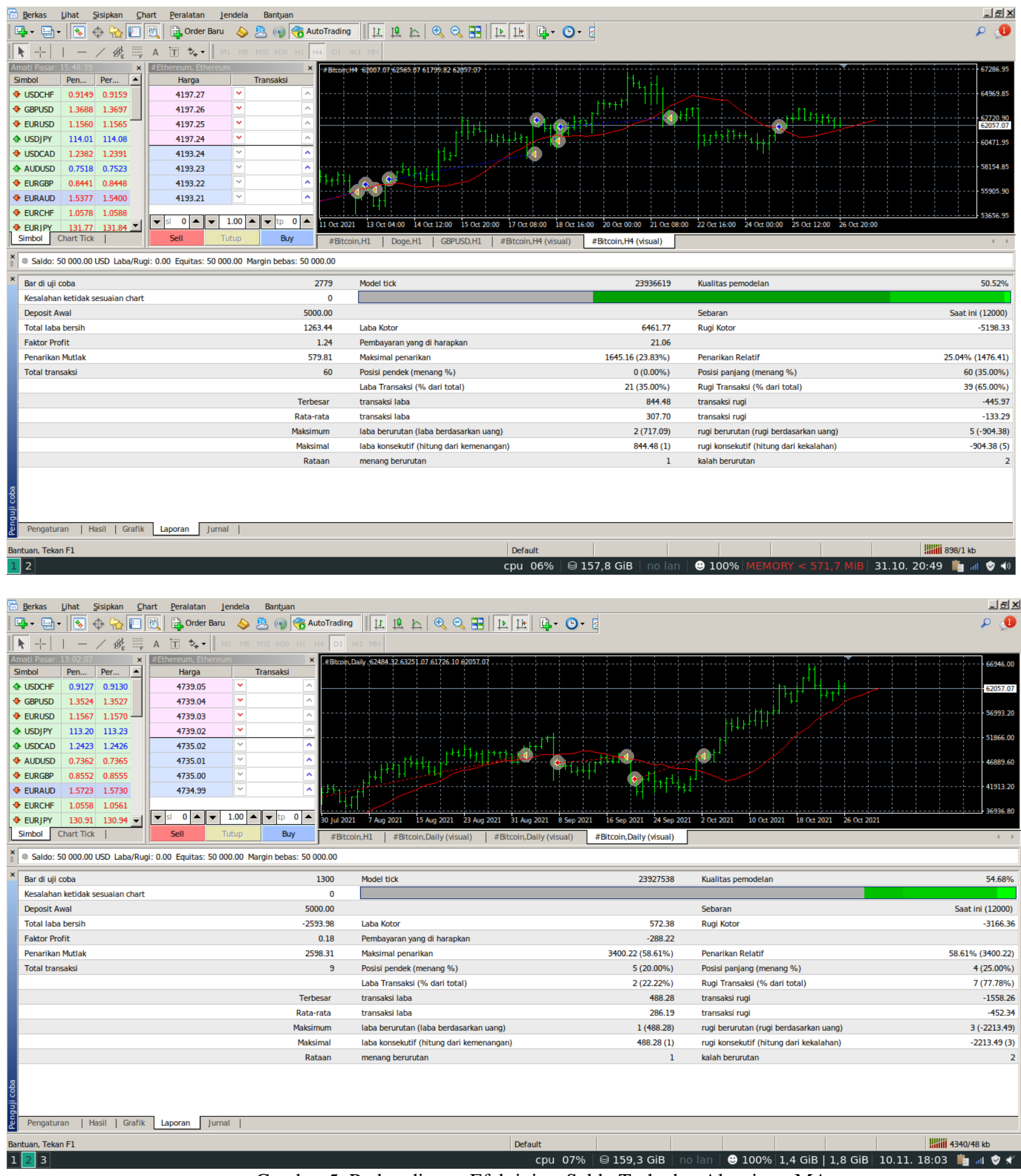

Gambar 5. Perbandingan Efektivitas Saldo Terhadap Algoritma MA

Pada gambar 5. terlihat bahwa efektivitas Algoritma Moving Average terhadap setiap time frime memiliki akurasi yang berbeda-beda. Periode dalam $\mathrm{H} 4$ adalah yang terbaik dalam penentuan prediksi efektivitas Algoritma Moving Average dengan menggunakan saldo paling minimum sebesar \$1200.

Tabel I. Hasil Akurasi

\begin{tabular}{|c|c|c|c|}
\hline Shift & Long & Short & Long \& Short \\
\hline D1 & 9 & 8 & 9 \\
\hline H4 & 21 & 15 & 25 \\
\hline Total Transaksi & 60 & 60 & 69 \\
\hline
\end{tabular}


JURSISTEKNI (Jurnal Sistem Informasi dan Teknologi Informasi) Vol 3, No.3, September 2021: Hal 41 - 48 ISSN. P: 2715-1875, E: 2715-1883

\begin{tabular}{|c|c|c|c|}
\hline Deposit Awal & 5000.00 & 5000.00 & 5000.00 \\
\hline
\end{tabular}

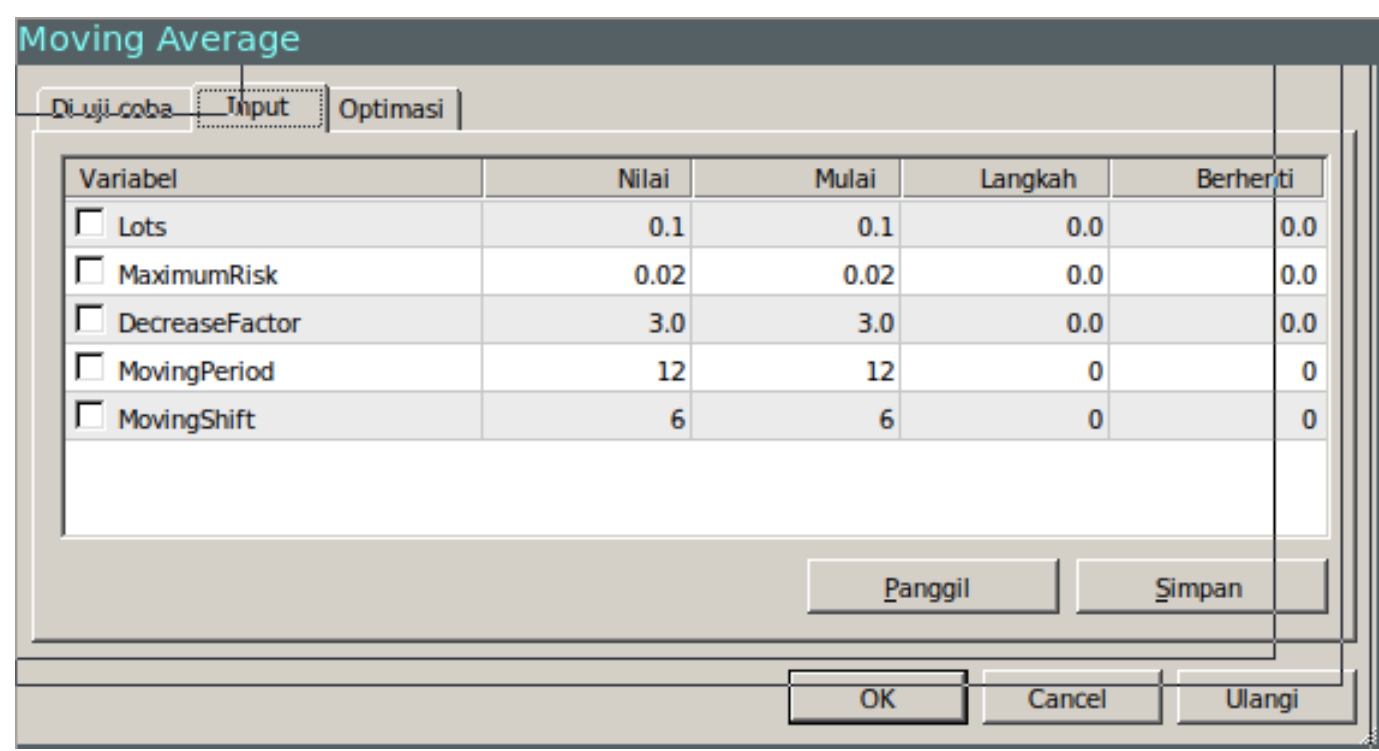

Gambar 6. Set Default Strategy Tester

IV. HASIL DAN PEMBAHASAN

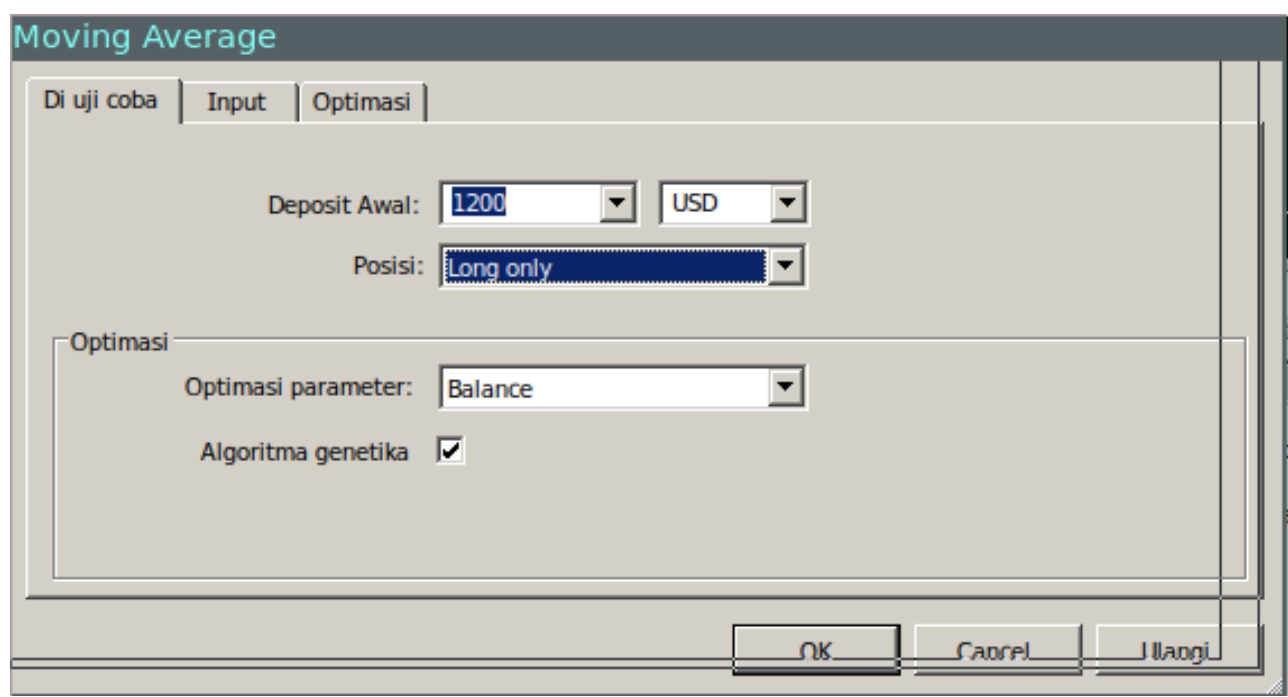

Gambar 6. Saldo 


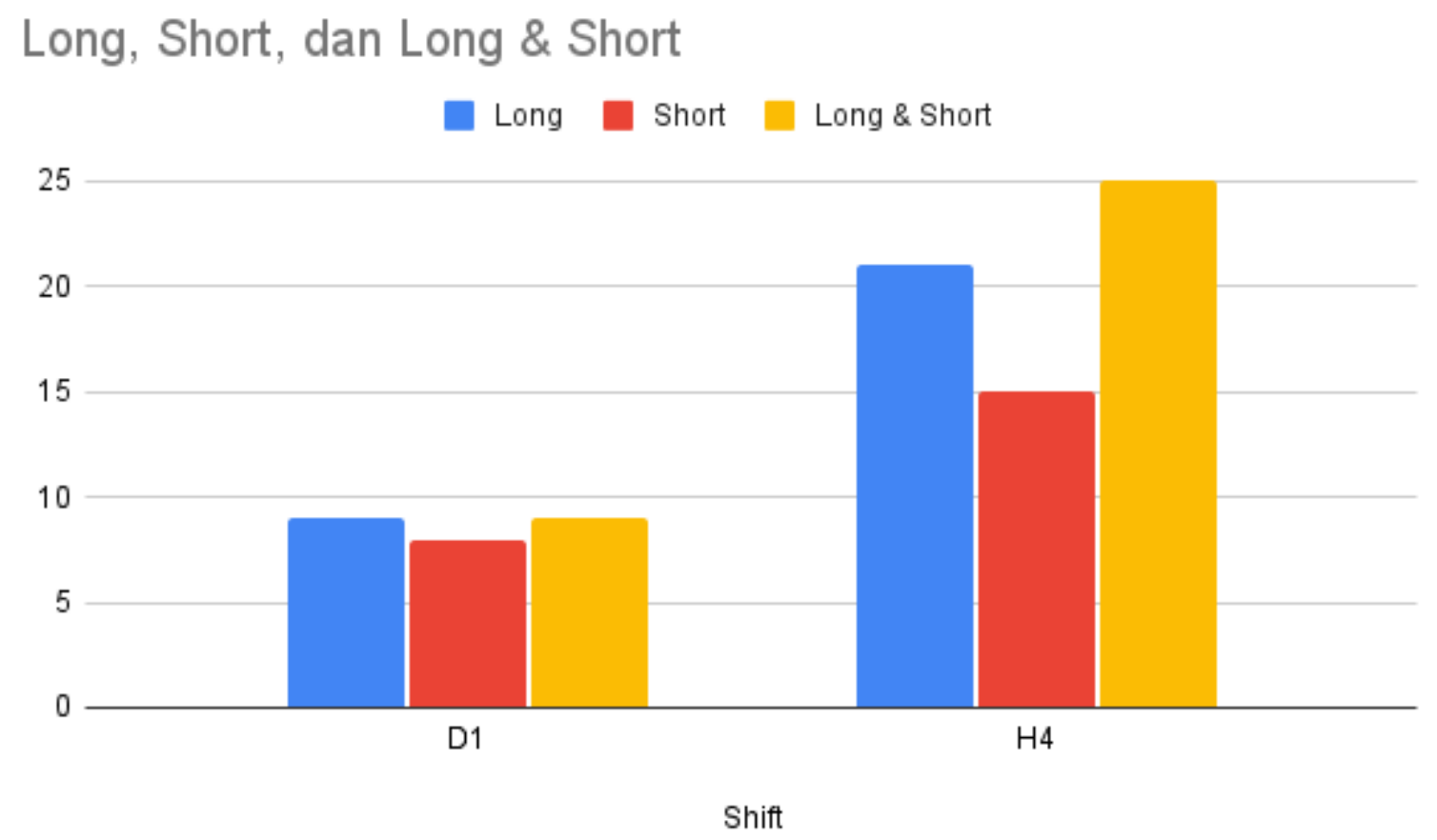

Gambar 7. Hasil Akurasi

Jumlah saldo minimum terhadap efektivitas Moving Average adalah $\$ 1200$ untuk mendapatkan profit maksimal tanpa pengurangan lebih lanjut dan pada timefrime $\mathrm{H} 4$ memiliki tingkat akurasi terbaik dalam penerapan Moving Average. Test Strategy Tester yang dilakukan adalah dengan menghitung periode H4 dengan 12 Candlesticks/Grafik atau selama 2 Hari yang menghasilkan pada time frime H4 Long Term Tecnique adalah yang terbaik dimana algoritma MA diterapkan dengan saldo paling minimum sebesar \$1200 untuk mendapatkan profit maksimal dari total transaksi 60 dengan tingkat kebenaran transaksi 21 dengan akurasi 35\%. Disisi lain, dengan teknik Long-Short Term memiliki tingkat kebenaran $21(36,23 \%)$ dari total transaksi 69.

\section{KESIMPULAN}

Pada penelitian ini penggunaan Moving Average terhadap efektivitas saldo memiliki tingkat akurasi 35\% dalam Long Term Tecnique dan 36,22\% dalam Long-Short Term Tecnique dan memiliki tingkat akurasi terbaik dalam timefrime H4, Dimana data dihitung dalam timefrime H4 selama 2 Hari atau dengan menghitung 12 Grafik Candlesticks menjadi penentu efektivitas Moving Average. Model algoritma MA masih perlu ditingkatkan untuk mendapatkan hasil lebih maksimal dengan pengembangan lebih lanjut dengan berbagai cara dan salah satunya adalah dengan menambah teknik prediksi atau mengkomparasi menggunakan berbagai macam teknik prediksi demi menghasilkan tingkat akurasi dan efektivitas di setiap periode. 
JURSISTEKNI (Jurnal Sistem Informasi dan Teknologi Informasi) Vol 3, No.3, September 2021: Hal 41 - 48 ISSN. P: 2715-1875, E: 2715-1883

\section{DAfTAR PUStaka}

[1] Works Cited, Kelly, Brian. The Bitcoin BIG BANG. Elex Media Komputindo, 2018.

[2] Sembiring, Falentino. "Analisis tingKat AKURaSi Algoritma Moving AVERAGE DALAM PREDiKSI PERGERAKAN UANG ELEKTRONIK BITCOIN” JUTISI: JURNAL ILMIAH TEKNIK INFORMATIKA DAN SISTEM INFORMASI

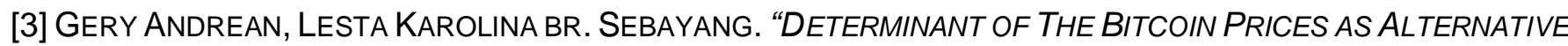
INVESMENT IN INDONESIA". DEPARTMENT OF ECONOMIC DEVELOPMENT, FACULTY OF ECONOMICS, SEMARANG STATE UNIVERSITY, INDONESIA.

[4] Siddhi Velankar, Sakshi Valecha, Shreya Majl. "Bitcoin Price Prediction using Machine LEARNING", DEPARTMENT OF ElECTRONICS \& TELECOMMUNICATION, PUNE INSTITUTE OF COMPUTER TECHNOLOGY, PUNE, MAHARASHTRA, INDIA

[5] LADISLAV KRISTOUFEK, "BITCOIN MEETS GOOGLE TRENDS AND WIKIPEDIA: QUANTIFYING THE RELATIONSHIP BETWEEN PHENOMENA OF THE INTERNET ERA", INSTITUTE OF ECONOMIC STUDIES, FACULTY OF SOCIAL Sciences, Charles University in Prague, Opletalova 26, 110 00, Prague, Czech Republic, EU, 2 INSTITUTE OF INFORMATION THEORY AND AUTOMATION, ACADEMY OF SCIENCES OF THE CZECH REPUBLIC, POD Vodarenskou VeZI 4, 182 08, Prague, Czech Republic, EU.

[6] JASON FERNANDO, OCTOBER 05, 2021. "MOVING AVERAGE", HTTPS://WWW.INVESTOPEDIA.COM/TERMS/M/MOVINGAVERAGE.ASP 